\title{
Las mutaciones de las sociedades del trabajo. De la liberación a la colonización del trabajo
}

\section{The mutations of labor societies. From liberation to the colonization of labor \\ José F. Durán Vázquez \\ Universidade de Vigo, España \\ $\left(\begin{array}{l}\text { Fecha de recepción: } 15 \text { de febrero de } 2021 \\ \text { Fecha de aprobación: } 25 \text { de mayo de } 2021\end{array}\right)$ \\ DOI: http://dx.doi.org/10.15304/ricd.3.14.7501}

\section{NOTAS BIOGRÁFICAS}

José F. Durán Vázquez es profesor de Sociología en la Universidad de Vigo. Es doctor y licenciado en Sociología, Licenciado en Geografía e Historia y en Ciencias Políticas. Sus investigaciones se orientan a analizar la genealogía y la transformación de las formas de legitimación y de integración en los mundos del trabajo, la educación y el consumo, así como las temporalidades sociales. Analizando también la influencia que tiene todo ello en la relación entre las generaciones y en la reproducción de las sociedades.

Contacto: joseduran@uvigo.es

\section{Resumen}

El siguiente texto tiene por objetivo mostrar los cambios experimentado por las sociedades del trabajo desde su momento de plenitud, después de la Segunda Guerra Mundial, hasta la crisis del sistema fordista de producción, en los años 70 de la pasada centuria, con el surgimiento de una nueva ética del trabajo. Y cómo estos cambios han supuesto el paso de una sociedad que entendía el trabajo como un medio de integración y de liberación, que conllevaba asimismo una serie de sacrificios, tal como pregonaba la ética puritana del trabajo, a otra que lo contempla, tal como lo hace la nueva ética del trabajo, como un medio de liberación no sacrificial, que invade cada vez más esferas de la vida colectiva, sin que queden ya apenas espacios sociales no colonizados por el trabajo.

Las apelaciones que hace la nueva ética del trabajo a la liberación de esta actividad de las imposiciones sacrificiales de la etapa anterior fordista, no han suscitado sin embargo una fuerte oposición, ni siquiera entre quienes son especialmente críticos con las actuales formas de organización del trabajo. Imbuidos ellos también del imaginario moderno del trabajo, que ha sacralizado esta actividad, elevándola al núcleo esencial de la vida individual y colectiva, tal como se mostrará en la primera parte del presente artículo, no son capaces de percibir otro modo de organizar la sociedad que no sea la que comienza y termina en el trabajo productivo.

No obstante, cuáles son las posibilidades y las limitaciones que tiene el trabajo como medio de integración y de liberación individual y colectiva, y qué implicaciones tiene todo ello para la reproducción cultural de las sociedades. Con estos interrogantes, y alguna tentativa de respuesta, concluirá el presente artículo. 


\section{Abstract}

The objective of the following text is to show the changes experienced by labor societies from their moment of fullness, after the Second World War, to the crisis of the Fordist system of production, in the 70s of the last century, with the emergence of a new work ethic. And how these changes have meant the passage from a society that understood work as a means of integration and liberation, which also entailed a series of sacrifices, as proclaimed by the Puritan work ethic, to another that sees it, such as it makes the new work ethic, as a non-sacrificial means of liberation, which invades more and more spheres of collective life, with hardly any social spaces left uncolonized by work. The appeals made by the new work ethic to the liberation of this activity from the sacrificial impositions of the previous Fordist stage, however, have not aroused strong opposition, not even among those who are especially critical of current forms of work organization. Imbedded they too with the modern imaginary of work, which has made this activity sacred, elevating it to the essential core of individual and collective life, as will be shown in the first part of this article, they are not capable of perceiving any other way of organizing society than the one that begins and ends in productive work.

However, what are the possibilities and limitations that work has as a means of integration and individual and collective liberation, and what are the implications of all this for the cultural reproduction of societies. With these questions, and some attempt to answer, this article will be concluded.

\section{Palabras clave}

Trabajo, modernidad, cambio, liberación, colonización.

Keywords

Work, modernity, change, liberation, colonization.

\section{Sumario}

1. Introducción

2. Cuando el trabajo no libera, sino que oprimía

3. La conformación del universo ideológico y social de las modernas sociedades del trabajo

3.1. El imaginario moderno del trabajo

3.2. La construcción de la moderna sociedad del trabajo

4. La colonización del trabajo liberado

4.1. Las imágenes del trabajo liberado

4.2. ¿Liberados por el trabajo o del trabajo?

5. Entre la liberación y la colonización del trabajo

6. Conclusión 


\section{Summary}

1. Introduction

2. When labor did not liberate, but oppressed

3. The conformation of the ideological and social universe of modern labor societies

3.1. The modern imaginary of labor

3.2. The construction of the modern society of labor

4. The colonization of liberated labor

4.1. Images of the liberated labor

4.2. ¿Liberateded for labor or from labor?

5. Between liberation and colonization of labor

6. Conclusion 


\section{INTRODUCCIÓN}

La importancia que ha adquirido el trabajo en nuestras sociedades es de tal magnitud que prácticamente resulta imposible tratar de dignificar cualquier actividad, por diferente que esta sea, sin referirla a esta categoría. Desde las jugadoras de fútbol femenino que reclaman la profesionalidad de su liga para equiparla a la masculina, hasta quienes solicitan el estatuto de empleo para actividades tales como la crianza y la educación de los hijos; en todos estos casos existe casi el mismo empeño por demostrar que estas actividades son también trabajo, porque contribuyen, de forma más o menos indirecta, a la productividad y a la riqueza colectivas.

Para comprender la razón de todo ello, es necesario salir del marco social y cultural que ha creado estas categorías, con un doble propósito. Primero comparativo, para mostrar como otras sociedades, diferentes a las nuestras, en particular todas las preindustriales, no estaban articuladas alrededor del trabajo. Segundo, histórico, para ver cómo se ha llegado a concebir el trabajo como la actividad por antonomasia que todo lo comprende, en unas sociedades, como las industriales, colonizadas casi enteramente por el trabajo.

Sólo así estaremos en condiciones de abordar el siguiente cometido del presente texto, a saber, comprender el sentido de las apelaciones que hace la nueva ética del trabajo, surgida en el contexto de la crisis del fordismo, a la liberación y a la realización de los sujetos. Así como el modo en el que estas apelaciones han sido integradas por los distintos tipos de trabajadores. De esta forma estaremos en situación de explicar por qué esta ética del trabajo no ha sido abiertamente contestada, ni siquiera por aquellas corrientes que, aun siendo profundamente críticas con las actuales formas de organización del trabajo, comparten sin embargo con los defensores de aquella ética el proyecto de una sociedad colonizada casi enteramente por el trabajo.

Todo lo anterior nos conducirá a una reflexión final sobre las consecuencias que tiene esta colonización del trabajo para la reproducción cultural de las sociedades, teniendo en cuenta las poten- cialidades y las limitaciones liberadoras e integradoras que posee dicha actividad.

\section{CUANDO EL TRABAJO NO LIBERABA, SINO QUE OPRIMÍA}

En todas las sociedades preindustriales, por diferentes que éstas fuesen, el trabajo no ocupaba un lugar central, sino que se integraba en los órdenes de la existencia considerados secundarios.

Esto significaba, en primer lugar, que esta actividad, desprendida de cualquier otro significado que no fuese el de procurar los medios materiales de existencia, no formaba parte del relato que unas generaciones se contaban a las otras como parte de una memoria colectiva que confería un determinado sentido al tiempo histórico y biográfico.

En efecto, el primero de esos tiempos, el histórico, se remitía a un origen vinculado a un pasado heroico, como en la Antigua Grecia, o a una particular tradición, como en la Roma Antigua, la que comenzaba en la época de la fundación de la ciudad, ab urbe condita (Revault D'allonnes, 2008, p. 73). En ese tiempo no estaba presente en absoluto el trabajo, sino la religión, la política, la guerra, el deporte o el arte (Veblen, 2004). Así, mientras que aquél era considerado la mayor fuente de deshonra, estas ocupaciones constituían distintos medios para alcanzar las más altas dignidades. Como sentenciaba el poeta romano Juvenal (2010), "considérese el mayor pecado preferir la mera existencia al honor, y para vivir perder las razones de la vida".

El tiempo biográfico tampoco estaba gobernado por las actividades productivas, motivos de la mayor deshonra, como antes se dijo, para los miembros de los grupos privilegiados. Pero aun cuando no quedase más remedio que trabajar para vivir, cargando con el peso de una vida poco honrosa, cuando no depreciable, el trabajo se integraba en el marco de otras esferas de la vida social y cultural que le otorgaban un mayor sentido. Tanto antropólogos (Mauss, 2009; Sahlins, 1983; Malinowski, 1973), como historiadores (Sewell, 1992; Polanyi, 1989; Veyne, 1987; Vernant, 1985; Vernant \& Vidal- Naquet, 1985; Le Goff, 1983), así lo han puesto de manifiesto.

Contemplado, pues, todo este proceso desde la perspectiva de las sociedades preindustriales, lo extraño es cómo el trabajo pasó de esa condición inferior y humillante, a otra, característica 
de las sociedades industriales, en la que se convirtió en el hecho antropológico fundamental, en uno de los principios esenciales de su credo ideológico y moral, y en la base de cualquier propuesta de reforma económica, política y social.

\section{LA CONFORMACIÓN DEL UNIVERSO IDEOLÓGICO Y SOCIAL DE LAS MODERNAS SOCIEDADES DEL TRABAJO}

El proceso a través del cual el trabajo dejó de considerarse una forma de vida inferior y humillante, para convertirse en la principal de todas las actividades, fue largo y complejo. Sintetizaremos esta complejidad en dos actos. En el primero, mostraremos cómo se configuró la ideología moderna del trabajo. En el segundo, describiremos como a partir de esta ideología, compartida por las principales élites de las sociedades modernas, se irán conformando las distintas sociedades del trabajo, a lo largo de un proceso dilatado y conflictivo.

\subsection{EL IMAGINARIO MODERNO DEL TRABAJO}

El despertar de la ideología moderna del trabajo se produjo en medio de una serie de acontecimientos que dieron lugar a una nueva visión del mundo. Entre ellos cabe destacar el surgimiento del Estado Moderno, el lento desarrollo de la burguesía, impulsada también por aquel Estado (Elias, 1993), la Reforma Protestante, particularmente la de raíz calvinista (Weber, 1998), la filosofía cartesiana y la Ciencia Moderna (Arendt, 1998). Todos ellos contribuyeron, desde su perspectiva, a que las élites de estas sociedades comenzasen a valorar cada vez más la actividad laboral como el medio principal para transformar el mundo, con el objetivo de procurar cotas mayores de prosperidad y de riqueza, y así proporcionar un mayor bienestar y felicidad para los seres humanos en la tierra.

Fueron las élites intelectuales las que, en relación con los intereses de la burguesía, primero iniciaron este camino, contribuyendo a conferir un nuevo sentido a aquellos intereses. Más tarde, cuando el grueso de los grupos sociales se incorpore a la dinámica de la sociedad industrial, en el curso de la industrialización de las sociedades, se verán influidos por este nuevo imaginario del trabajo. Enfrentados a sus respectivas circunstancias, estos grupos irán reconfigurando dicho imaginario, que adquirirá así un nuevo sentido, proyectando una determinada imagen sobre la realidad social en la que se encontraban inmersos (Taylor, 2014, p. 282).

Una de las primeras etapas en la construcción de la ideología moderna del trabajo la recorrió John Locke a finales del siglo XVII, cuando legitimó la propiedad en relación con el trabajo. El trabajo, en efecto, y no la herencia o la conquista, era el que debía otorgar acceso legítimo a la propiedad, de una forma considerada digna y honorable. "Cualquier cosa- escribió- que el ser humano saca del estado en que la naturaleza la produjo y la dejó, y la modifica con su labor y añade a ella algo que es de sí mismo, es, por consiguiente, propiedad suya" (Locke, 2006, pp. 56-57)

En este mismo periodo- entre la segunda mitad del siglo XVII y la primera del XVIII- las élites vinculadas a los intereses políticos de las Monarquías absolutas, preocupadas por conseguir medios materiales para sus conquistas, elaboraron una serie de ideas que dieron lugar al pensamiento mercantilista. Para el Mercantilismo el trabajo útil era aquel que producía los recursos materiales necesarios para engrandecer el reino, y por ello tenía que convertirse en uno de los criterios apropiados para organizar la sociedad (Genovesi, 1786).

En todos estos planteamientos, no obstante, el trabajo todavía no se había enseñoreado del mundo, porque su productividad aún se consideraba que dependía de la fértil y sagrada madre naturaleza (Locke, 2006, p. 56; Genovesi, 1786, cap. VII). Era de ella, en efecto, de donde precisamente los Fisiócratas (movimiento intelectual del siglo XVIII de origen francés) sostenían que procedía toda la riqueza, aunque fuese el ser humano quien por medio de su trabajo la ponía en valor. A este valor contribuían también sin embargo, y no en menor medida, los propietarios de la tierra, cuando invertían en ella para hacerla más productiva (Meek, 1975; Quesnay, 1974; Weulersse, 1968).

Pronto, no obstante, todas estas concepciones, que todavía condicionaban la productividad del trabajo a la de la naturaleza, comenzarán a cambiar. Y ese cambio ocurrirá primero, a partir de la segunda mitad del siglo XVIII, en aquellos lugares, que, como Inglaterra, iniciaron el proceso de industrialización más tempranamente. Será primero Adam Smith, considerado el padre de la economía, y más tarde David Ricardo, quienes lo protagonizaron. En efecto, ambos elaboraron un pensamiento económico en el que 
el trabajo era el gran demiurgo creador de toda cuanta riqueza cada nación posee (Smith, 1997).

No obstante, ese carácter demiúrgico será aún mayor cuando la productividad del trabajo ya no se encuentre limitada, como aún sostenía Adam Smith, por la necesidad de producir "las cosas necesarias y útiles para la vida que se consumen anualmente en la nación" (Smith, 1997, p. 5). Porque, tal como afirmará posteriormente David Ricardo, en una sociedad capitalesta, en el que la riqueza sólo puede ser una, la que se vincula al valor de los productos intercambiados en el mercado, éste no puede ser el cometido principal del trabajo. Su finalidad ha de ser otra, la de producir esos valores de cambio, que serán mayores o menores en función de la facilidad o de la dificultad con la que son creados mediante el trabajo. De ahí, que la actividad laboral deba proseguir sin desmayo para generar más y más riqueza, más y más valores de cambio, en un proceso que tiene que ser continuamente renovado (Ricardo, 2003).

Quién más profunda y agudamente criticó el pensamiento económico ricardiano fue Marx, al considerar que era el producto de la mistificación del mercado capitalista, y con él de todas las mercancías que en él se intercambian, entre ellas el trabajo. Éstas aparecían, así, como fetiches ante quienes las adquirían, como cosas con un valor propio, por mucho que ese valor se lo confiriese el mercado (Marx, 1999). No obstante, a pesar de la profunda agudeza con la que Marx destapó la urdimbre ideológica que encubría el carácter verdadero del trabajo en el mercado capitalista, él mismo fue quien más contribuyó a sacralizarlo, al convertirlo en el origen de la humanidad y de la sociedad (Marx, 2001, pp. 151-152). Desde este punto de vista, cualquier actividad humana digna de consideración será vista como trabajo, sin que las demás ocupaciones merezcan apenas ningún aprecio.

A finales del siglo XIX la herencia socialista y marxista será integrada con la liberal por el sociólogo francés Émile Durkheim, en el contexto de la III República Francesa, dentro de su propuesta de reforma de la sociedad del trabajo. Este proyecto de reforma, que coincidía en buena medida con el de las élites políticas del periodo, se proponía fundar un orden social que, sin cuestionar la productividad del trabajo industrial, ni la iniciativa individual, la conjugase con una cierta justicia social (Lukes, 1984). En este contexto, el trabajo desempeñaría un papel fundamental. No sólo era la principal fuerza productiva, sino también la actividad a partir de la cual debía estructurarse el conjunto de la colectividad en consonancia con los principios sancionados por la Revolución Francesa (Durkheim, 1995).

A medida que avance el proceso de industrialización de las sociedades, este imaginario del trabajo será interiorizado gradualmente por la población asalariada. No obstante, este será un proceso largo y complejo, que suscitó la oposición de aquellos que estaban imbuidos por la cultura preindustrial del trabajo.

\subsection{LA CONSTRUCCIÓN DE LA MODERNA SOCIEDAD DEL TRABAJO}

El proceso de construcción de las modernas sociedades del trabajo fue el producto de la confrontación de la ideología liberal y de la socialista-marxista, y de éstas con la propia realidad a la que se enfrentaban, la emergencia de la sociedad industrial del trabajo. Por un lado, la ideología liberal, que penetró y modeló la conciencia burguesa, tuvo reformularse en contacto con esta realidad, lo que se tradujo en una serie de reformas políticas destinadas a regular el mercado de trabajo, cuando la burguesía comprendió que, si dicho mercado se dejaba liberado a sí mismo, se producirían desórdenes y revueltas sociales que podrían precipitar la caída de las propias sociedades de mercado (Polanyi, 1989).

Por el otro, la ideología socialista-marxista alentó y dio sentido a las revueltas obreras urbanas que comenzaron a producirse a partir de las dos primeras décadas del siglo XIX (Sewell, 1992, pp. 261 y 307-308). Unas revueltas que estaban también motivadas porque la cultura del trabajo de estos trabajadores urbanos, abiertamente preindustrial, poco tenía que ver con la que quería imponerles las élites de la sociedad industrial (Thompson, 1979).

Todo lo cual dificultaba su integración en el mercado de trabajo. Esta integración se produjo más tarde, a partir de la segunda mitad del siglo XIX, a través de la intervención de una serie de instituciones socializadoras, tales como las eclesiásticas, las educativas, las políticas y, por supuesto también, las fabriles (Castel, 2001; Pollard, 1987). Todas ellas convergieron en la necesidad de crear un orden económico, social, político y moral, articulado alrededor del trabajo.

Desde el punto de vista jurídico-político la creación de este orden implicaba delimitar las condiciones del trabajo asalariado, y con respecto a él las del paro. Trabajadores fueron así considerados todos los que tenían una ocupación regular y retribuida; y parados los que la habían 
tenido, y que ahora se encontraban, contra su voluntad, sin trabajo. El trabajo adquirió así la categoría jurídica de empleo, con respecto a la cual se creó la de desempleo (Topalov, 1994).

Después de la Segunda Guerra Mundial, en el marco de los nacientes Estados del Bienestar, estas categorías se convirtieron en una de las bases sociales fundamentales de la ciudadanía democrática (Marshall \& Bottomore, 1998). El trabajo, en su forma moderna de empleo, adquirió así el carácter de hecho económico, social, político y moral por excelencia. No sólo era contemplado como el motor de una productividad y de una riqueza que crecían sin pausa, y como el medio principal para ascender individual y socialmente (Alonso, 2001; Castel, 2001), en digna competencia con los semejantes (Beveridge, 1947, p. 320). Era también la actividad que daba acceso a una serie de derechos nunca antes vista, que conformaron un nuevo estatuto de la ciudadanía (Rubio Lara, 1991; Ashford, 1989). El empleo se había convertido, en fin, en la actividad integradora y liberadora por excelencia.

No obstante, dicha liberación tenía como contrapartida una serie de sacrificios, que a nadie se le ocultaban. "Toda libertad tiene su responsabilidad", dijo William Beverigde, uno de los grandes inspiradores del Estado del Bienestar británico (1989, p. 243), la de trabajar duro cada uno de los días de la semana (Castel, 2001, p. 330), sin reparar mucho en gustos y vocaciones personales. Para la mayoría de los trabajadores todo ello, en efecto, poco contaba. Contaban más otras satisfacciones vinculadas a la reproducción y a la movilidad social (De Miguel, 2000; Muñoz Carrión, 1994; De Lora, 1965).

Paradójicamente, fue después- a partir de mediados de los años 70, con la crisis del sistema de producción fordista, cuando el trabajo ya no podía colmar muchas de estas aspiraciones-, cuando se recubrió de una serie de encantamientos (Gorz, 2000). Encantamientos que, ocultando los sacrificios que comportaba la integración laboral, no hacían más que prometer nuevas liberaciones

\section{LA COLONIZACIÓN DEL TRABAJO LIBERADO}

\subsection{LAS IMÁGENES DEL TRABAJO LIBERADO}

Como antes se ha señalado, a partir de mediados de los años 70 la crisis y posterior transformación del modelo laboral y productivo fordista, que había protagonizado el crecimiento económico continuado posterior a la Segunda Guerra Mundial, acompañado del casi pleno empleo, dio lugar a otro sistema, el postfordista, en el que el incremento de la productividad ya no iba seguido del aumento y de la estabilidad del empleo (Beck, 2000 y 2006; OCDE, 2000; Prieto, 1999; Comisión Europea, 1995). En este contexto, en el que el trabajo se hizo más escaso y precario (Díaz Salazar, 2003), emergió una nueva ética del trabajo, destinada a legitimar esta situación laboral, cuyo discurso procedía tanto del imaginario moderno del trabajo como de aquel otro vinculado a la cultura del consumo (Boltanski \& Chiapello).

Esta nueva ética fue elaborada y difundida sobre todo por los intelectuales vinculados al denominado nuevo management ${ }^{2}$, y también por las principales instituciones políticas, tanto nacionales como internacionales, aunque sus discursos, como se ha señalado, poco tenían de novedosos. Su novedad residía en el propósito al que servían, legitimar y reactivar la relación laboral postfordista, confiriéndole nuevos sentidos.

En este contexto, del trabajo ya no se destacará su vertiente más sacrificial, tal como lo hiciera la anterior ética puritana de raíz calvinista (Weber, 1998). Por el contrario, de dicha actividad se resaltará- de acuerdo con la ideología moderna del trabajo, sobre todo la de raíz socialistamarxista (Durán Vázquez, 2011), y asimismo con los valores de la cultura del consumo-, sus aspectos más expresivos, que el sistema de producción fordista, rutinario y monótono, había reprimido, alienando a quienes debieran estar liberados por el trabajo. En la nueva empresa- escriben los autores del nuevo management- "cada individuo es invitado a aportar su sentido personal" (Landier, 1992, pp. 182-183), para así "desarrollarse sin exclusión ni alienación" (Genelot, 1992, p. 194). Por lo que frente a la "moral de sujeción" fordista, la empresa postfordista sólo reclama una "moral de cooperación libremente aceptada" (Landier, 1992, p. 177).

Si el trabajo ya no se representa como un deber sacrificial en espera de futuras recompensas, más o menos diferidas en el tiempo, tampoco tiene ya demasiado sentido separarlo de otros ámbitos de la vida, como ocurría en las organizaciones fordistas ¿Cómo puede, en efecto, una actividad vacacional y creativa, confinarse en los estrictos límites de la racionalidad productiva? "Cabría preguntarse- afirman los autores del management- si esta frontera entre trabajo y no trabajo no debe entrar a formar parte de los numerosos arcaísmos que necesitamos 
superar". Pues "la empresa pide cada vez más o exige unas cualidades más personales que la simple competencia profesional" (Landier, 1992, pp. 161-162).

Ahora bien, ¿se sienten de verdad reclamados los sujetos por las llamadas que hace la nueva ética del trabajo a que participen activamente en los distintos escenarios laborales, poniendo en juego todas las facetas de su personalidad, para poder así realizarse?

\section{2 ¿LIBERADOS POR EL TRABAJO O DEL TRABAJO?}

Del mismo modo que a partir de mediados de los años 80 había emergido, tal como se ha visto, una nueva ética del trabajo, cuyo propósito era legitimar las nuevas relaciones laborales surgidas del postfordismo, en este mismo periodo se estaba produciendo otra transformación en el ámbito de las culturas del trabajo. La relación entre uno y otro fenómeno, el de la ética y las culturas del trabajo, permitirá comprender por qué aquella ética ha sido integrada de un modo particular por quienes tienen determinados valores y determinadas actitudes laborales.

Para una importante parte de los sujetos esta cultura del trabajo ya no guarda mucha relación con la de sus antecesores fordistas. Para éstos últimos el trabajo era un acto sacrificial al que había que entregarse diariamente en espera de futuras recompensas, tanto las que se recibían en el propio ámbito laboral como aquellas otras que se traducían en un determinado poder de compra, expresión de distintas posiciones de clase (Sennett, 2001; Bell, 1977). De esta cultura participan actualmente sobre todo los trabajadores varones más maduros y poco cualificados; los antiguos ganapanes, que, precisamente por ello, se sienten incomprendidos por sus empleadores, y también por quienes pregonan las virtudes laborales de la nueva ética del trabajo, que a ellos poco les dicen, porque apenas coinciden con las que habían dado significado a sus vidas. Como incomprendidos se sienten también por sus propios descendientes, cuyas actitudes laborales poco tienen que ver ya con las suyas. Superados por un escenario laboral en constante cambio, que poco les estima y que apenas entienden; sin fuerzas y sin demasiadas razones que oponer, que no sean las del lamento por lo que han vivido, y que ahora ven como se les escapa, pocas alternativas tienen a las que acogerse, porque el trabajo es precisamente su vida (Ramos, 2008).

Alternativas que sí tienen aquellas otras personas que perciben el trabajo instrumentalmente, como un medio para otros fines, y en especial aquellos relacionados con el mundo del ocio y el consumo. Para esa gran parte de la juventud con empleos habitualmente precarios (Benedicto, 2016), el trabajo es, en efecto, la actividad que les permite obtener los recursos monetarios necesarios para realizarse en esas otras esferas, en las que se sienten mucho más reconocidos (Balderson, Burchell, Kamerade, Wang \& Coutts, 2020; Lloyd, 2012; Ramos, 2008). Por lo demás, su actitud es de espera; pero no la de una espera desesperada, sino aquella otra que, mientras tanto, se empeña en aprovechar al máximo ese tiempo llenándolo de múltiples vivencias (Cuzzocrea, 2018; Pais, 2009). A este grupo de jóvenes los discursos de la nueva ética del trabajo, con sus Ilamamientos a la implicación y al compromiso laboral, como camino para el desarrollo de todas sus potencialidades, poco, pues, pueden decirles (Farrugia, 2018).

Como sí les dicen a aquellos otros trabajadores que disponen de ocupaciones relacionadas con sus cualificaciones y vocaciones personales, bien remuneradas, y con estabilidad y oportunidades de ascenso. Para estos trabajadores creativos (Florida, 2004) ${ }^{3}$, su profesión es una oportunidad de realización personal, de poner a prueba todas sus vocaciones, todos sus talentos y cualificaciones, al margen de jerarquías burocráticas y de aburridas rutinas laborales. El trabajo es, pues, para ellos una especie de aventura, una ocasión para disfrutar y de aprender a hacer cada día cosas nuevas, y también una oportunidad para expresar todo lo que de más auténtico hay en ellos. De ahí que no establezcan demasiadas distinciones entre su vida fuera y dentro del trabajo, porque el trabajo es su vida y su vida es trabajo (Robin \& Shireen, 2019; Farrugia, 2018; Bergua, 2016; Valenzuela, Reygadas y Cruces, 2015).

No es extraño, pues, que a estos trabajadores los discursos de la nueva ética del trabajo les resulten mucho más cercanos. Sus apelaciones a la realización personal, en entornos laborales flexibles, horizontales y abiertos, que posibilitan cambiar cada día de tarea, ofreciendo lo que de más personal y auténtico hay en ellos, no pueden dejar de resultarles cercanas. Porque guardan relación con sus respectivos estilos de vida, en los que el trabajo no es contemplado como una actividad sometida a un espacio y a un tiempo 
racionalizados, sino como una experiencia creativa que posibilita la construcción de biografías independientes y autónomas, como si cada uno fuese el artista de su propia vida (Bauman, 2009).

Mientras que estos últimos trabajadores conciben sus actividades laborales como experiencias liberadoras, los anteriores (tanto los más maduros con una cultura del trabajo fordista, como los que tienen una cultura del trabajo más instrumental) sienten más bien que colonizan sus vidas. Los más maduros, porque ya no se identifican con un relato que en otro tiempo había dado sentido a sus biografías, pero que ya no es el suyo (Ramos, 2008; Sennett, 2001). Los más jóvenes con trabajos precarios, porque les quita tiempo para realizarse y ser reconocidos en sus otros mundos de vida (González-Anleo Sánchez, 2010).

Ahora bien, existen algunas profesiones, como por ejemplo las docentes, que se situarían entre una y otra cultura del trabajo. En efecto, por un lado, comparten algunas de las características atribuidas a las profesiones creativas, tales como su dimensión vocacional y expresiva, su desempeño más o menos libre y autónomo, o su carácter innovador (Bergua, 2016). Pero, por el otro, paradójicamente, a medida que en las últimas décadas se han legitimado cada vez más por su condición creativa, han ido perdiendo el carácter independiente y autónomo que tuvieron en otras épocas (Durán Vázquez y Duque, 2019, p. 143). Cuanto más se invita así a los docentes a que sean innovadores, más esta innovación se rige por los parámetros establecidos por las disciplinas psicopedagógicas (Laval, 2004; Varela, 1992), y exigidos por las instituciones públicas (Rychen y Salganik, 2004; OCDE, 1998: 17-31). Lo que les obliga a estar continuamente formándose en conocimientos que se supone que ya no tienen (Gimeno, 2008). Pierden así uno de los atributos más señalados de su autonomía, el dominio de un saber que otros no poseen, pues en verdad ya no son maestros de nada, sino sólo aprendices. De pertenecer a una profesión liberal, que liberaba a quienes la desempeñaban, la docencia ha pasado así a integrarse en el marco de otras muchas actividades salariales, con sus mismas incertidumbres e inseguridades.

En estas circunstancias, cabe preguntarse si el trabajo puede ser la actividad liberadora por excelencia, tal como proclaman los portavoces de la nueva ética del trabajo, y propagan también en muchas ocasiones los medios de comunicación. Como destacados representantes de la industria cultural, estos medios, en efecto, contribuyen a la difusión de este imaginario del trabajo, muy cercano a la ética laboral postfordista (Virno, 2003, p. 56), que lo presenta recubierto de todos los atributos de la creatividad y de la liberación.

Ahora bien, ¿tiene sentido proyectar esta imagen del trabajo, cuando tantas personas no se sienten así liberadas? Pregunta que no entraña cuestionar el papel fundamental que debe desempeñar esta actividad en la generación de riqueza, y en la ordenación de las sociedades, de una manera considerada igualitaria y justa. Sino interrogarse acerca de si la integración y la liberación de los sujetos deben fiarse casi enteramente a dicha actividad, limitando otras formas de integración y de liberación, fundamentales también para la continuidad de las sociedades.

\section{ENTRE LA LIBERACIÓN Y LA COLONIZACIÓN}

¿Puede el trabajo colmar todas las aspiraciones sociales e individuales; todos los anhelos de integración y de liberación de los sujetos, o, por el contrario, existen otras esferas de la vida humana que pueden también liberarnos e integrarnos, y a las que las sociedades del trabajo deben dar por ello también cabida?

Para la ideología moderna del trabajo, que ha moldeado las modernas sociedades industriales, la actividad laboral poseía la potencialidad de ordenar la sociedad de forma justa, solidaria y armónica, posibilitando el desarrollo de cada uno de sus miembros de una manera libre y autónoma. Aunque, de acuerdo con la ética puritana del trabajo, todo ello siempre comportaba una cierta entrega sacrificial en espera de futuras recompensas. Para las corrientes del imaginario moderno del trabajo de inspiración socialista y marxista, esta entrega ya no sería necesaria, cuando desapareciesen la propiedad privada y la división del trabajo. Entonces, ya nadie querría liberarse del trabajo, sino por el trabajo ${ }^{4}$, porque el trabajo, en efecto, posibilitaría el desarrollo de todas las dimensiones de la naturaleza humana de forma libre, igualitaria y solidaria.

La actual ética del trabajo se ha legitimado presentando también dicha actividad como un acto más liberador que sacrificial, aunque no por ello menos orientado al incremento constante de la productividad. Ha fusionado así, de una manera particular y propia, la herencia liberal y la socialista-marxista. Una herencia, esta última, de la que participan también los que son más críticos con las actuales sociedades del empleo. 
Una crítica que se propone, por un lado, desprender la actividad laboral de su condición exclusivamente productivista, que le ha conferido el mercado capitalista, para considerarla desde una perspectiva más amplia, que englobe todas las potencialidades humanas (Noguera, 2002). Y, por el otro, atribuir la condición de trabajo, y por tanto la integración en el marco jurídico-político de la sociedad del empleo, a todas aquellas ocupaciones que se cree contribuyen también al incremento de la riqueza (Durán Heras, 2012).

Para los que siguen la corriente liberal de la ideología moderna del trabajo, la liberación consistiría sobre todo en hacer más productivas económicamente las distintas ocupaciones laborales, capacitando a quienes las desempeñan, para que así sean más independientes y autónomos.

No obstante, ni unos ni otros, tanto críticos como defensores de las actuales sociedades del empleo, son capaces de advertir otra forma de organizar la sociedad que no sea la que se supedita casi enteramente a la actividad laboral (Méda, 1998). No aciertan a ver otras vías de integración y de liberación que no sean las que el trabajo, que todo lo comprende, señala (Arendt, 1998, p. 17; Thompson, 1979).

Todo ello nos conduce a dos importantes consideraciones. Primera, que es necesario tener en cuenta tanto las potencialidades como las limitaciones del trabajo productivo para organizar la sociedad 5 . Potencialidades para la generación de riqueza, y también para la integración social y el desarrollo de los sujetos; limitaciones para su desarrollo e integración en otras esferas de la vida. La segunda, que el objetivo de la productividad no debe ser el que anime casi exclusivamente la participación de los sujetos en el mundo laboral.

Prestemos un poco más de atención a cada una de estas dos cuestiones. Comenzando por la primera, es evidente que las actuales sociedades del trabajo han concedido tal preeminencia a esta actividad, que todas las demás han pasado a depender casi enteramente de ella. No solamente el universo del consumo, destinado a liberar tiempo de trabajo productivo para consumirlo productivamente, en un constante proceso de destrucción creativa (Bauman, 2009, p. 93), de permanente renovación de los objetos, que hace de su novedad su principal y casi única razón de ser. También el mundo de la educación, cada vez más guiado por el objetivo de la permanente adaptación de los conocimientos a una esfera productiva que cambia sin cesar (Gimeno, 2008; Laval, 2004). Y asimismo el de la familia, que se articula crecientemente en función de las exigencias que impone dicha esfera, dificultando cada vez más las funciones de crianza y educación de los hijos, que tienen que ser muchas veces externalizadas. Exigencia que se traslada también a los miembros de la pareja, acuciados por un mundo laboral que les demanda más y más tiempo; más y más entrega, a la que no pueden renunciar, a riesgo de perder oportunidades, ya no sólo de progresar, sino de permanecer en el empleo (Beck y Beck-Gernsheim, 2001).

Ahora bien, si la esfera laboral se impone sobre los demás mundos de vida de los sujetos, desnaturalizándolos, ella misma también, obedeciendo casi exclusivamente a la lógica productivista que imponen los mercados, se empobrece cada vez más. No podemos olvidar, en efecto, lo que otros asumieron mucho antes que nosotros, que el mercado no tiene capacidad para organizar el trabajo, porque no es una simple mercancía más (Offe, 1990; Polanyi, 1989). Pero también tendríamos que asumir que el trabajo es mucho más que la tarea realizada, y aunque esta pueda entusiasmar a algunos, muchos otros tendrán que desempeñarla sin tanto entusiasmo, porque razón productiva obliga.

Tienen que existir, pues, otras razones para trabajar, además de las que imponen los mercados y exige la tarea. Razones relacionadas con la seguridad y las oportunidades de progresar en el empleo, de acuerdo con normas claras y estables, y también las vinculadas con la sociabilidad en el trabajo.

El trabajo no debiera ser ni mucho más ni mucho menos que esto. Ni mucho más, porque no podemos aspirar a integrarnos y a liberarnos enteramente a través de esta actividad, cuando hay otras que también nos liberan y nos integran. Pero tampoco menos, porque menos es reducirlo a una ocupación animada casi únicamente por la voluntad productivista de los mercados. Y menos es también lo que paradójicamente se presenta como más, la posibilidad de realizar todas las facetas de nuestra personalidad a través de la tarea realizada. Una personalidad que muchas veces quedará incompleta, sometida a los imperativos de la productividad.

\section{CONCLUSIÓN}

A lo largo del presente texto hemos mostrado como las sociedades modernas del trabajo se han conformado alrededor de esta actividad, en 
relación con el programa económico, político y social de la modernidad, hacer una sociedad más rica y más próspera, y también más igualitaria, libre y solidaria. Un programa que sin embargo exigía también, tal como proclamaba la ética puritana del trabajo, una serie de sacrificios, en espera de futuras recompensas.

Durante una etapa de la modernidad, particularmente aquella comprendida entre el final de la Segunda Guerra Mundial y los años 70 del pasado siglo, este programa se hizo realidad en muchos de sus extremos, en un contexto de crecimiento económico continuado y de expansión del Estado del Bienestar.

Cuando este crecimiento se vio interrumpido, a partir de mediados de los años 70 , también lo hicieron las ilusiones que habían sido depositadas en el trabajo. Éste ha tenido así, que ser reencantado por la nueva ética del trabajo, en relación con el imaginario procedente de la cultura del consumo y de la ideología moderna del trabajo. Un reencantamiento que, ocultando los aspectos más sacrificiales asociados a dicha actividad, ha llamado la atención sobre aquellos otros relacionados con la liberación creativa de los sujetos. Ahora bien, a este reencantamiento ya no se oponen, ni siquiera aquellos que son especialmente críticos con las actuales formas de organización del trabajo. Imbuidos como están del imaginario moderno del trabajo, del cual reclaman, asimismo, su parte legítima de herencia, proyectan también sobre esta actividad todos sus anhelos liberadores, sin reparar demasiado en los sacrificios integradores que siempre ha exigido. Unos y otros, críticos y defensores de las actuales sociedades del trabajo, no conciben así otra forma de organizar la sociedad que no sea la que descansa casi enteramente en dicha actividad, supeditando a ella todas las demás esferas de la vida, que o bien quedan recluidas en la oscuridad del ámbito privado, o convertidas en distintas formas de empleo.

La consecuencia de todo ello es que otros modos de integración y de liberación, y por tanto de reproducción de las sociedades, e incluso su misma continuidad, se ven amenazadas. que participaron alrededor del $70 \%$ de la población (Carabaña, 1999).

2 Las obras del management comenzaron a proliferar en la segunda mitad de los años 80 y la primera mitad de los 90 del pasado siglo. Se debieron a una serie de autores conectados con el mundo de la empresa que celebraban las virtudes de la nueva organización postfordista del trabajo, en un lenguaje emparentado con la cultura del consumo y con la ideología moderna del trabajo.

3 Estos trabajadores creativos, según análisis relativamente recientes, supondrían en torno al $24 \%$ de la población trabajadora, cifra inferior a la de otros países del norte de Europa y de EE.UU, pero notablemente superior a la de Portugal, en donde representarían alrededor del 15\% (Bergua et al, 2016: 71).

4 Resulta llamativa la contradicción en la que desde este punto de vista cae el propio Marx, impropia, como dice Hannah Arendt, de un pensador de su talla (Arendt, 1998: 116). En efecto, cuando escribe sobre las bondades de la futura sociedad comunista, señala como la principal de ellas la liberación- aunque sólo sea parcialmente- de los seres humanos del trabajo, la actividad que estaba precisamente destinada a construirlos libre y autónomamente. Pues en dicha sociedad podrán "cazar por la mañana, pescar por la tarde, criar ganado al atardecer, criticar después de cenar, sin convertirse nunca en cazadores, pescadores, pastores 0 críticos" (Marx, 1999 I, Libro III).

${ }^{5}$ La productividad del trabajo fue uno de los conceptos clave del discurso laboral moderno, lo que llevó a diferenciar entre trabajo productivo y no productivo. Esta productividad estuvo relacionada unas veces con la generación de valores de uso (particularmente en las primeras etapas de la conformación de la ideología moderna del trabajo y en la corriente socialista-marxista), y otras, sin embargo, con la producción de valores de cambio (en la versión liberal de dicha ideología). No obstante, por encima de esta diferencia, había otra también fundamental. En efecto, para quienes pensaron el trabajo en una sociedad preindustrial, su condición productiva suponía tanto una potencialidad como una limitación, pues la entrega a esta actividad implicaba la retirada de otros órdenes de la vida considerados más elevados; mientras que para quienes lo hicieron en la sociedad industrial abría enormes posibilidades para el desarrollo individual y colectivo (Durán Vázquez, 2011 y 2006; Díez, 2001).

\section{NOTAS}

1 Como muestra de la importancia que tuvo el trabajo como mecanismo de movilidad social, las cohortes de españoles nacidas en las primeras 8 décadas del siglo XX experimentaron movilidad intergeneracional vertical, de la 


\section{REFERENCIAS BIBLIOGRÁFICAS}

- Arendt, H. (1998). La condición humana. Paidós.

- Ashford, D. (1989). La aparición de los Estados de Bienestar. Ministerio de Trabajo y SS.

- Balderson, U., Burchell, B., Kamerade, D., Wang, S. \& Coutts, A. (2020). An exploration of the multiple motivations for spending less time at work. Time $\&$ Society, 30(1), 55-77.

https://doi.org/10.1177/0961463X20953945

- Bauman, Z. (2009). El arte de la vida. Paidós.

- Bauman, Z. (2000). Trabajo, consumismo y nuevos pobres. Gedisa.

- Beck, U. (2006). La sociedad del riesgo. Hacia una nueva modernidad. Paidós.

- Beck, U. y Beck-Gernsheim, E. (2001). El normal caos del amor. Paidós.

- Beck, U. (2000). Un nuevo mundo feliz. Paidós.

- Bell, D. (1977). Las contradicciones culturales del capitalismo. Alianza Editorial.

- Benedicto, J. (dir.) (2016). Informe Juventud en España 2016. Instituto de la Juventud.

- Bergua, J.A. (dir.) (2016). Creatividad. Números e imaginarios. CIS.

- Beveridge, W. (1989). Pleno empleo en una sociedad libre. Ministerio de Trabajo y SS.

- Beveridge, W. (1947). La ocupación plena. FCE.

- Boltanski, L.; Chiapello, È. (2002). El nuevo espíritu del capitalismo. Akal.

- Carabaña, J. (1999). Dos estudios sobre movilidad intergeneracional. Fundación Argentaria.

- Castel, R. (2001). Las metamorfosis de la cuestión social. Paidós.

- Cicerón (1995). Los Oficios. Espasa Calpe.

- Comisión Europea (1995). Créer des emplois. Oficina de Publicaciones de las Comunidades Europeas.

- Cuzzocrea, V. (2018). Moratorium or waithood? Forms of time-taking and the changing shape of youth. Time \& Society, 28(2), 567-586. https://doi.org/10.1177/0961463X18763680.

- De Lora, C. (1965). Juventud española actual. Ediciones y Publicaciones españolas.

- De Miguel, A. (coord.) (2000). Dos generaciones de jóvenes 1960-1998. Ministerio de trabajo y Asuntos Sociales.

- Díaz Salazar, R. (coord.) (2003). Trabajadores precarios. HOAC.
- Díez, F. (2001). Utilidad, deseo, virtud. La formación de la idea moderna de trabajo. Península.

- Durán Heras, MํA. (2012). El trabajo no remunerado en la economía global. Fundación BBVA.

- Durán Vázquez, J.F. y Duque, E. (2019). Las transformaciones de la educación. De la tradición a la modernidad hasta la incertidumbre actual. Dykinson.

- Durán Vázquez, J.F. (2011). La metamorfosis de la ética del trabajo. Constitución, crisis y reconfiguración de la ética del trabajo en la modernidad tardía. Andavira.

- Durán Vázquez, J.F. (2006). La construcción social del concepto moderno de trabajo. Nómadas: Revista Crítica de Ciencias Sociales y Jurídicas, 13(1), 219-236.

https://revistas.ucm.es/index.php/NOMA/article/ download/NOMA0606120219A/26703/0.

- Durkheim, É. (1995). La división del trabajo social. Akal.

- Elías, N. (1993). El proceso de civilización. FCE.

- Farrugia, D. (2018). The formation of young workers: The cultivation of the self as a subject of value to the contemporary labour force. Current Sociology, 67(1) 1-17. https://doi.org/10.1177/0011392118793681.

- Florida, R. (2004). The rise of the creative class. Basic Books.

- Genelot, D. (1992). Manager dans la complexité. Insep éditions.

- Genovesi, A. (1786). Lecciones de comercio, o bien de economía civil (III Vols.). Viuda de Ibarra, hijos y compañía.

- Gimeno Sacristán, J. (2008). Educar por competencias ¿Qué hay de nuevo? Morata.

- González-Anleo Sánchez, J.M. (2010). Los valores de los jóvenes y su integración socio-política. En J. González-Anleo.J., González Blasco, P. (coords.). Jóvenes españoles 2010 (pp. 9-114). Fundación SM.

- Gorz, A. (2000). Miserias del presente, riqueza de lo posible. Paidós.

- Juvenal (2010). Sátiras. Alianza Editorial.

- Grañeras Pastrana, M.; Parras Laguna, A. (coords.) (2009). Orientación educativa: fundamentos teóricos, modelos institucionales y nuevas perspectivas. CIDE. 
- Landier, H. (1992). Hacia la empresa inteligente. Deusto.

- Laval, Ch. (2004). La escuela no es una empresa. El ataque neoliberal a la enseñanza pública. Paidós.

- Le Goff, J. (1983). Tiempo, trabajo y cultura en el Occidente Medieval. Taurus.

- Le Goff, J. (1969). La civilización del Occidente Medieval. Juventud.

- Lloyd, A. (2012). Working to live, not living to work: Work, leisure and youth identity among call centre workers in North East England. En Current Sociology, 60(5), pp. 619-635. https://doi.org/10.1177/0011392112445623.

- Locke, J. (2006). Segundo Tratado sobre el Gobierno Civil. Alianza Editorial.

- Lukes, S. (1984). Émile Durkheim. Su vida y su obra. SXXI.

- Malinowski, B. (1973). Los argonautas del Pacífico. Península.

- Marshall, T.; Bottomore, T. (1998). Ciudadanía y clase social. Alianza Editorial.

- Marx, K. (2001). Manuscritos de economía y filosofía. Alianza Editorial.

- Marx, K (1999). El Capital (Vol. I). FCE.

- Mauss, M. (2009). Ensayo sobre el don. Forma y función del intercambio en las sociedades arcaicas. Katz.

- Méda, D. (1998). El trabajo, un valor en peligro de extinción. Gedisa.

- Meek, R. (1975). La Fisiocracia. Ariel.

- Muñoz Carrión, A. (1994). Aspiraciones y objetivos existenciales. En Serrano, M. (dir.) (1994). Historia de los cambios de mentalidades de los jóvenes entre 1960-1990 (pp. 207-220). Injuve.

- Noguera, J. (2002). El concepto de trabajo y la teoría social crítica. Papers, 68, 141-168. http://dx.doi.org/10.5565/rev/papers/v68n0.144 $\underline{5}$.

- OCDE (2000). Estudio sobre el empleo (Parte I). Universitat Autónoma.

- OCDE (1998). L'école à la page. Formation continue et perfectionnement professionnel des enseignantes. OCDE.

- Offe, C. (1990). Contradicciones en el Estado del Bienestar. Alianza Universidad.

- Pais, J.M. (2009). A Juventude como Fase de Vida: dos ritos de passagem aos ritos de impasse. Saúde e Sociedade, 18(3), 371-381.

\section{https://doi.org/10.1590/S0104-}

12902009000300003 .

- Polanyi, K. (1989). La gran transformación. La Piqueta.

- Pollard, S. (1987). La génesis de la dirección de empresa moderna. Estudio sobre la Revolución Industrial en Gran Bretaña. Ministerio de trabajo y S.S.

- Prieto, C. (ed.) (1999). La crisis del empleo en Europa. Germanía.

- Quesnay, F. (1974). Le tableau économique y otros estudios económicos. Revista de Trabajo.

- Ramos Torre, R. (2008). Los tiempos vividos. En Prieto, C., y Ramos Torre, R. (eds.). Nuevos tiempos de trabajo. Entre la flexibilidad competitiva de las empresas y las relaciones de género (pp. 107-385). CIS.

- Revault D’allonnes, M. (2008). El poder de los comienzos. Ensayo sobre la autoridad. Amorrortu.

- Ricardo, D. (2003). Principios de economía política y tributación. Pirámide.

- Robin, S. \& Shireen K. (2019). Valuing creativity, feeling overworked and working hours: Male workers and the New Spirit of Capitalism. Time \& Society, 29(1) 51-73. https://doi.org/10.1177/0961463X18820730.

- Rubio Lara, M.J. (1991). La formación del Estado Social. Ministerio de Trabajo y SS.

- Rychen, D.S. y Salganik, L.H. (eds.). (2004). Definir y seleccionar las competencias fundamentales para la vida. FCE.

- Sahlins, M. (1983). Economía de la Edad de Piedra. Akal.

- Sennett, R. (2001). La corrosión del carácter. Las consecuencias personales del trabajo en el nuevo capitalismo. Anagrama.

- Sewell, W.H. (1992). Trabajo y revolución en Francia. Taurus.

- Smith, A. (1997). Investigación sobre la naturaleza y causas de la riqueza de las naciones. FCE.

- Taylor, Ch. (2014). La era secular(Vol. I.). Gedisa.

- Thompson, E.P (1979). Tiempo, disciplina de trabajo y capitalismo industrial. En Thompson, E.P. Tradición, Revuelta y conciencia de clase (pp. 239293). Critica.

- Topalov, Ch. (1994). Naissance du chômeur. 1880 1910. Albin Michel.

- Valenzuela, H., Reygadas, L. y Cruces, F. (2015). Mi trabajo es mi vida. La incrustación de los mundos de la vida y del trabajo en empresas españolas. REIS, (150), 191-210. 
http://dx.doi.org/10.5477/cis/reis.150.191.

- Varela, J. (1992). Categorías espacio temporales y socialización escolar: del individualismo al narcisismo. Revista de Educación, (298), 7-29. https://www.educacionyfp.gob.es/dam/jcr:67470 c31-6999-4b0e-8a4ded483ceb652b/re2980100486-pdf.pdf.

- Veblen, T. (2004). Teoría de la clase ociosa. Alianza Editorial.

- Vernant, J.P. (1985). Mito y pensamiento en la Grecia Antigua. Ariel.

- Vernant, J.P. ; Vidal-Naquet, P. (1985). Travail et Esclavage en Grece Ancienne. Complexe.

- Veyne, P. (1987). El imperio Romano. En Ariés. P.H. y Duby, G. (eds.). Historia de la vida privada (Vol. I) (pp. 20-227). Taurus.

- Virno, P. (2003). Gramática de la multitud. Para un análisis de las formas de vida contemporáneas. Traficantes de sueños.

- Weber, M. (1998). La ética protestante y el espíritu del capitalismo. En Weber, M. Ensayos sobre sociología de la religión. (Vol. I) (pp. 25-231). Taurus.

- Weber, M. (1993). Economía y sociedad. FCE

- Weulersse, G. (1968). Le mouvement physiocratique en France (2 Vols.). Mouton. 